\title{
Familial and interpersonal relations in patients with obsessive compulsive disorder (OCD)
}

\begin{abstract}
The present qualitative study aims to examine the nature of familial and interpersonal relations in the lives of patients with Obsessive Compulsive Disorder (OCD). It aimed to explore the perspective of patients with OCD regarding the behavior of their parents, siblings and extended family towards them. The constructivist paradigm and a collective case study method were employed to explore the nature of familial and interpersonal relations of patients with OCD. Two participants were selected through homogenous purposive sampling strategy from Mayo Hospital Lahore, Pakistan. In-Depth interviews were used as a method to gather the information that were tape recorded and later transcribed into Urdu language. The obtained data was analyzed by conducting within and cross-case analyses. The verification procedures employed included clarifying researcher's bias and rich-thick description. The results depicted that the relationships of patients with their parents were of tight-knit type and relations with their siblings were of obligatory and detached type. Moreover, other interpersonal relationships (i.e., friends and cousins) of patients were of reciprocal type.
\end{abstract}

Keywords: familial relations, interpersonal relations, OCD
Volume 4 Issue 3 - 2015

\author{
Nayab Ali,Anza Javed Butt, Iram Zehra \\ Bokharey \\ A Department of Clinical Psychology, University of the Punjab, \\ Pakistan
}

Correspondence: Nayab Ali, MS in Clinical Psychology, Centre for Clinical Psychology, University of the Punjab, Lahore, Pakistan. House no 537, Block-C, Faisal Town, Lahore, Pakistan, Email nayyabalil6@gmail.com

Received: September 09, 2015 | Published: November 17, 2015

\section{Introduction}

According to WHO (1996), Obsessive Compulsive Disorder (OCD) is considered as one of the most incapacitating and a leading cause of disability among anxiety disorders. ${ }^{1}$ OCD constitutes either obsessions or compulsions or commonly both. An obsession refers to unwanted or intrusive thoughts, urges or mental images which enter one's mind repeatedly whereas compulsions refer to repetitive behaviors or mental acts that one feels compelled to act upon. ${ }^{2}$ Sometimes, the term 'ritual' is also used as synonymous of compulsion but that usually means one's those behaviors that are observable to others. These behaviors or rituals are time consuming and adversely impact one's family relationships (such as marital discord); cause financial burden, frustration, anxiety and anger among family members ${ }^{3-6}$ disrupt social relationships ${ }^{7}$ interfere with one's leisure time activities ${ }^{8}$ and achievement of educational and/or occupational goals. ${ }^{7,9}$

People suffering from OCD might also actively or furtively involve their care giver or family member in their rituals and avoidance behaviors that is frustrating for them because their involvement make things even more worse. ${ }^{10}$ This involvement refers to accommodating the OCD. ${ }^{11}$ Denial or disbelief is another way how families respond to OCD. As a result, families often experience complex and uncomfortable emotions (e.g., anxiety, anger and frustration) that affect their relationships in addition to their family life. ${ }^{3}$ Sometimes, guilt is felt by the parents about their child suffering from OCD. What needs to be understood by them is that they can play a vital role in their child's recovery process and maintenance of good mental health. ${ }^{4}$ It is because being hopeful positively relates with active problem solving and high social support but relates negatively with coping strategies involving denial and disengagement. ${ }^{12}$ Among all the categories of anxiety disorders, people suffering from OCD show greater impairment in family functioning. ${ }^{13,14}$ OCD fears are of irrational nature and caregivers sometimes expect from the sufferer that they should have greater control over their avoidance behaviors and rituals. This type of attribution relates to the family's high expressed emotions (i.e., mainly criticism or hostility towards the sufferer). ${ }^{15}$
Silverstein and Bengston (1997) proposed typology of intergenerational family relationships. One of the types is the "tightknit" type relationship, which constitutes high emotional closeness i.e. family members live fairly close enough to each other, involves frequent interaction, high levels of mutual help and support among them. The other extreme of relationship is "detached type" that consists of low levels of closeness or being connected in all solidarity measures. Between these (tight-knit and detached) types of relationships, there are three other classes of family relationships. The "sociable" and "intimate-but-distant's" types consisting low or absence of functional exchange and high affinity that suggest potential for future support and exchange respectively. Next is the "obligatory" type that involves a high connectedness (proximity and interaction) with an average level of functional exchange but on the other hand has low level of emotional attachment. ${ }^{16}$

Since, OCD relates with high shame and fears' regarding rejection, the concealment of obsessions is part of the said disorder. ${ }^{17}$ Families might also take part in the process by protecting both the family and the sufferer from experiencing embarrassment and rejection inflicted by untrusted circle offriends and relatives in addition to the suffering of the disorder. Stigma sometimes called "a second illness" also plays a vital role. ${ }^{18}$ Experiencing stigma results in social isolation and may lead to extreme social exclusion. A stigmatized individual is devalued and comes across limited life chances. ${ }^{18,19}$

In a study it was found that the individuals with OCD stated that their symptoms negatively influenced their social life. ${ }^{20}$ However, individuals can vary greatly in their degree of impairment. Some patients with OCD are totally unable to maintain any social relations on account of severe contamination fears whereas some have satisfying interpersonal relationships. ${ }^{10}$ According to Mani, Interpersonal relationships refer to social associations, connections, or affiliations between two or more people. There are three types of friendship: reciprocity, receptivity and association. Reciprocity is characterized by loyalty, self-sacrifice, mutual affection and generosity. This relationship involves give and take relationship from both ends. The second type "receptivity" is characterized by imbalance in the 
giving and receiving of rewards. The third type is "association", this relation is transitory, and more like a friendly relationship than a true friendship. ${ }^{21}$

OCD patients tend to experience impairment in the familial functioning and in social interaction. Keeping in mind the problems faced by the patients in their familial and social interaction, the present study was planned to explore the familial and interpersonal relationships of patients with OCD.

\section{Method}

The paradigm used in this study was constructivism and the strategy employed was case study method to explore the lived experiences of patients with OCD. The participants were chosen through homogenous purposive sampling strategy and the sample consisted of two unmarried participants (man and woman). Both belonged to middle socio-economic status, diagnosed with Obsessive Compulsive Disorder (DSM-IV-TR) with an age of 18years, and no prior history of treatment. The participants were taken from psychiatry ward of Mayo Hospital Lahore, Pakistan.

First, the semi-structured questionnaire was constructed keeping in view the relevant literature for interview guide. After recruiting the participants, their in-depth semi structured interviews were tape recorded and transcribed. Embedded case analysis was done for indepth exploration of lived experiences of patients with OCD in the context of familial and interpersonal relations. Within case analyses were followed by cross case analyses (Figure 1). In within case analyses, free textual analysis was done in which themes and sub-themes were generated. After analyzing both cases, cross case analyses was done and common themes and patterns were identified. Verification refers to a process that continues during the whole procedure i.e. the data collection, analysis and report writing to ensure standards, validity and reliability of the research. Rich thick description and clarifying researcher's bias were used for verification of research.

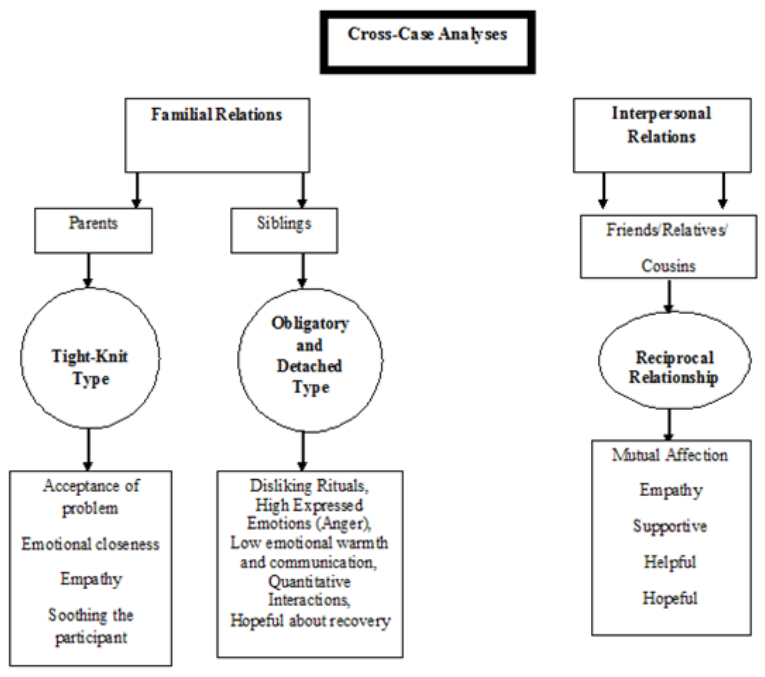

Figure I cross case analyses.

A written informed consent was taken from both participants and confidentiality was assured. The participants were informed about the research purpose and its method. The participants were given the right to withdraw from the participation at any time. They were also informed that fictitious names would be used instead of real ones in the write-up of study. No monetary compensation was offered. Lastly they were also told that if desired free counseling services would be offered to them in case they became distressed during the course of interviews.

\section{Results}

\section{Familial relations}

Relation with mother- tight knit type: Both participants shared tight-knit type relationships with their mothers because their mothers empathized with them and were quite hopeful about the management of the OCD due to which the environment of mutual sharing and help prevailed. As reported by Ali, his mother said, "Get more close to him (Ali), talk more softly with him, get him treated so that he makes his future better". Similarly Sana shared, "My mother's behavior is absolutely fine with me, since the beginning of disorder. She knows that I am not well".

Relations with father- detached type vs. tight-knit type: Sana shared detached relationship with her father. When Sana developed OCD her father expressed emotions of anger by using harsh language and high tone of voice on daily basis. According to her father, she was deliberately causing her problems. Therefore, Sana's relationship with her father was devoid of emotional closeness and warmth or any fruitful communication. Moreover, there was lack of understanding of Sana's problem by her father and there seemed to be no element of mutual respect and care between them. All these factors place Sana's relationship with her father to fall in the category of detached. As Sana reported.

"When I started performing rituals, he used to get furious. He yelled at me so that neighbors listen to what I am doing. According to him I did it deliberately and told me that when I would get married my in-laws would not like me to indulge in these rituals".

Ali shared tight knit relationship with his father. When severity of OCD increased, his father was worried about how it might influence his studies. Eventually, he developed feelings of empathy and showed concern to seek treatment of Ali's problems. His father understood $\mathrm{OCD}$ as a disease and empathized with his present condition. As Ali reported, "I was more close to my father than before. He understood my condition and thus I took treatment for it. He wanted me to get recovered. This implied that he understood my illness".

Relation with siblings- detached type vs. obligatory type: Sana had detached relationship with her siblings. When she began to indulge in washing rituals for long hours, her siblings showed feelings of hatred for her rituals and expressed their disliking by showing high expressed emotions (anger). They made Sana aware of the financial problems that arose as a result of her excessive use of water. As she reported, "I go near water, spend hours, then they say why I am wasting water like this. This is how they started hating me. They express their anger. They asked repeatedly why I spent so much time in the washroom. They said that because of me they have to pay more amount of bill for water."

Ali had obligatory type of relationship with his siblings. He had frequent negative interactions with his siblings. However, his sibling's response towards his problems of OCD was derogatory. They denied his problems and showed hostility towards him. His siblings found it embarrassing to be related to a person who had such problems. Due to these reasons, his siblings wanted him to seek treatment and become normal. As he reported, "When my problem started they ridiculed me and called me 'back gear'. They get very irritated when they see me in this condition. They feel bad that their brother is indulging in 
such behaviors. So they get really upset with me. They say that they have also been through this period of life and did not experience such symptoms. Why am I so different? How this can happen to me?"

\section{Interpersonal relations}

Relations with friends-reciprocity: Both participants shared reciprocal relations with their friends. Initially, Ali hid his problems from his friends due to shame, embarrassment, and fear of rejection. He confined himself into his home and decreased his social interactions. However, upon sharing his OCD problems, his friends showed empathy and tried to normalize his problems. His friends showed more concern towards his betterment and were hopeful about the management of his problems. As he reported, "He started understanding that I have a problem. He told me that he would help me get treatment. In fact he forced me quite a lot for taking treatment. Initially during my illness, I had stopped meeting my friends".

On the contrary Sana had introvert traits. She had only one friend with whom she used to share her problems. However, she hid her problem of OCD as she feared she might lose her close friend. Sana was fearful that if her friend found out about her symptoms she would hate her just as her family did. As she stated, "I did not inform her so that she does not start hating me just like my family members and my friendship might not end".

Relation with relatives/cousins: Both participants had reciprocal relationship with their relatives and cousins. Ali had hid his problem of OCD from his relatives and cousins. Therefore there was no difference in his relationships with cousins and relatives before and after developing OCD. As Ali reported, "They still perceive me the same as before".

Sana also shared healthy relations with all her cousins. They were aware of her problem as well as treatment and they all supported her As she reported, "I was in contact with my cousins before illness. My cousin's behavior is fine with me. They know about my illness and my treatment, and they support me".

\section{Discussion}

In the light of the results obtained from the analyses of two cases under study, the nature of familial relations was found out to be of tight-knit type. The father of one participant showed empathy and concern towards the disease. They were also hopeful about the recovery of participant and brought him to hospital for treatment. The findings are supported by the study of ${ }^{12}$ in which being hopeful was found to positively related to active problem solving and high social support.

However, one of the participants experienced detached relationship with her father because he frequently expressed anger, and exhibited denial of the participant's problems. Schlosser ${ }^{3}$ put forwarded those families who face behaviors and rituals associated with OCD, usually experience uncomfortable and complex type of emotions. As the OCD symptoms get more severe, the high expressed emotions elicited the by family also increased. In result, relationships get strained and affect family life. Our findings are also supported by the study of Amir et al., ${ }^{4}$ who found that the parents of children suffering with OCD might also experience anxiety because of their own maladaptive assumptions. Consequently, they exhibited difficulty in coping regarding important domains in life.

The perceived relations of OCD patients with siblings ranged from obligatory type to detached type. The siblings expressed denial of disease by expressing feelings of disliking and high expressed emotions. However, they had interactions with each other. Schlosser ${ }^{3}$ also put forwarded families of the people suffering from OCD reacts with denial or disbelief. They actually experience hard time understanding why the individual suffering with OCD cannot stop eliciting the ritual that is the clear cause of unhappiness for everyone in the family. As a result of these irrational OCD fears, many caregivers expect from them that they should exert greater control over their avoidance behaviors and rituals. This type of attribution leads the caregivers to enact high expressed emotion (i.e., mainly criticism or hostility towards the sufferer)..$^{13}$ Therefore, siblings responded to the participants with high expressed emotions in the present study.

The interpersonal relationships perceived by the participants were reciprocal. Initially they concealed their OCD due to shame, embarrassment and fear of rejection. According to Schulze \& Angermeyer ${ }^{18}$ and Finzen ${ }^{19}$ experiencing stigma brings along social isolation and lead towards extreme social exclusion. A stigmatized individual feels devalued and benefits from limited life opportunities. Initially, both participants concealed their disorder to avoid stigmatization and social isolation. However, upon disclosing their problems of OCD, their friends showed empathy and attempted to normalize their problems.

\section{Conclusion}

In the light of above discussion, it seems that the perceived familial and interpersonal relations tend to show a wide range. As the institution of family is quite strong in our sociocultural context, it should be incorporated in the psychological assessment as well as therapeutic intervention for OCD patients. Therefore, studies which focus on the impact of psychiatric disorders on the relationship of patients with their families, such as the present one are a dire need, as they would help in devising indigenous therapy modules regarding OCD. As the sample of the study was rather small, future research on this subject needs to be done on larger samples.

\section{Acknowledgements}

The authors would like to thank Ms. AimanJavaid and Ms. Farhanaljaz for referrals of the participants in this project. The authors would also like to thank Ms. Sidra Ali, Consultant Clinical Psychologist and Research Associate at Institute of Clinical Psychology, University of Management and Technology, Lahore, Pakistan for providing additional guidance in data analyses in this research project. The authors would also like to thank Ms. HumairaNaz, Consultant Clinical Psychologist and Assistant Professor at Centre for Clinical Psychology, University of the Punjab, Lahore, Pakistan for providing technical guidance.

\section{Conflicts of interest}

Author declares there are no conflicts of interest.

\section{Funding}

None.

\section{References}

1. Doron G, Kyrios M. Obsessive Compulsive Disorder: A review of possible specific internal representations within a broader cognitive theory. Clin Psychol Rev. 2005;25(4):415-432.

2. American Psychiatric Association (APA). Diagnostic and statistical manual of mental disorders (4th edn), Washington, DC, USA. 2000. 
3. Schlosser S, Black DW, Gaffney G, et al. The impact of obsessive compulsive disorder on the family: Preliminary findings. J Nerv Ment Dis. 1998;186(7):440-442.

4. Amir N, Freshman M, Foa EB. Family distress and involvement in relatives of obsessive-compulsive disorder patients. J Anxiety Disord. 2000;14(3):209-217.

5. Magliano L, Tosini P, Guarneri M, et al. Burden on the families of patients with obsessive-compulsive disorder: a pilot study. Eur Psychiatry. 1996;11(4):192-197.

6. Chakrabarti S, Kulhara P, Verma SK. The pattern of burden in families of neurotic patients. Soc Psychiatry Psychiatr Epidemiol. 1993;28(4):172-177.

7. Koran LM. Quality of life in obsessive-compulsive disorder. Psychiatr Clin North Am. 2000;23(3):509-517.

8. Antony, Martin M, Bieling, et al. Psychometric properties of the 42item and 21-item versions of the Depression Anxiety Stress Scales in clinical groups and a community sample. Psychological Assessment. 1998;10(2):176-181.

9. Leon AC, Portera L, Weissman MM. The social costs of anxiety disorders. Br J Psychiatry Suppl. 1995;(27):19-22.

10. Simpson HB, Liebowitz MR, Foa EB. Post-treatment effects of exposure therapy and clomipramine in obsessive-compulsive disorder. Depress Anxiety . 2004;19(4):225-233.

11. Rector NA, Bartha CA, Kitchen K, et al. Obsessive Compulsive Disorder: A Guide for people with Obsessive-Compulsive Disorder and their families. 2001.

12. Geffken GR, Storch EA, Duke DC, et al. Hope and coping in family members of patients with obsessive-compulsive disorder. J Anxiety Disord . 2006;20(5):614-629.
13. Frost RO, Steketee G, Williams LF, et al. Mood, personality disorder symptoms, and disability in obsessive compulsive hoarders: A comparison with clinical and non-clinical controls. Behav Res Ther. 2000;38(11):1071-1081.

14. Lochner C, Mogotsi M, du Toit PL, et al. Quality of life in anxiety disorders: A comparison of obsessive-compulsive disorder, social anxiety disorder, and panic disorder. Psychopathology. 2003;36(5):255-262.

15. Steketee G, Van Noppen B, Lam J, et al. Expressed emotion in families and the treatment of obsessive compulsive disorder. In Session: Psychotherapy in Practice. 1998;4(3):73-91.

16. Bengtson VL, Lowenstein A. Global Aging and Challenges to families. Aldine de Gruyter Canadian Journal of Sociology Online . 2003;387.

17. Newth S, Rachman S. The concealment of obsessions. Behav Res Ther. 2001;39(4):457-464.

18. Finzen A. Stigma, Stigmabewältigung, Entstigmatisierung. PsychiatrPrax. 2000;27:316-320.

19. Schulze B, Angermeyer MC. Subjective experiences of stigma: A focus group study of schizophrenic patients, their relatives and mental health professionals. Soc Sci Med. 2003;56(2):299-312.

20. Sorensen CB, Kirkeby L, Thomsen PH. Quality of life with OCD. A self reported survey among members of the Danish OCD Association. Nord J Psychiatry. 2004;58(3):231-236.

21. Honeycutt JM, Bryan SP. Scripts and communication for relationships. Peter Lang Publishing, Inc. New York, USA. 2011. 